\title{
Study of pharmacoeconomic analysis of drugs used in the treatment of bronchial asthma at tertiary care hospital of Northern India
}

\author{
Garima Adhaulia ${ }^{1 *}$, Shireen Barua ${ }^{1}$, Suryakant ${ }^{2}$, Ajay Verma ${ }^{2}$, Rajendra Nath ${ }^{1}$, \\ Amod Kumar Sachan ${ }^{1}$, Rakesh Kumar Dixit ${ }^{1}$
}

\{1epartment of Pharmacology and Therapeutics $\}$ \{2Department of Respiratory Medicine $\}$ K.G.M.U., Lucknow, Uttar Pradesh, INDIA. Email: drgarima.26@gmail.com

\section{$\underline{\text { Abstract }}$}

\begin{abstract}
Context: Asthma is a chronic disease requiring prolong treatment. Higher and unaffordable drug prices result in the noncompliance and treatment failure. So, pharmacoeconomic studies are important in evaluating and assessing the most costeffective treatment options for the patient. Aims: To perform a cost minimization and cost effectiveness analysis study for the various treatment alternatives being prescribed to the asthma patients. Settings and Design: The study was carried out at the Department of Respiratory Medicine, K.G.M.U., Lucknow. Patients diagnosed with bronchial asthma were screened and recruited for the study after satisfying the inclusion exclusion criteria and taking written informed consent. Methods and Material: A prospective observational study was undertaken for cost-minimization and cost-effectiveness analysis. Minimum and maximum cost in Rupees (INR) of various prescribed anti asthmatic agents was expressed as percentage cost variation. Cost of treatment/prescription/month and improvement in $\mathrm{FEV}_{1}$ was calculated by average cost effectiveness ratio (ACER) and incremental cost effectiveness ratio (ICER). Statistical analysis : Cost were mentioned in mean and standard deviation. Results: Among single prescribed group, maximum and minimum \% cost variation was seen with steroids and anticholinergics. For FDCs, maximum and minimum \% cost variation was seen with combination of leukotriene receptor modifiers and anti-histaminics and combination of steroid and LABA. Cost per unit improvement in $\mathrm{FEV}_{1}$ (ACER) was highest with four drug combination of [Steroid + LABA, salbutamol (SABA), anticholinergic and LTRA] and lowest with four drug combination of [Steroid + LABA, SABA + anticholinergic, methylxanthines and LTRA]. Conclusions: Pharmacoeconomic studies are important in choosing an effective and economical therapy alternative for the patient population.

Key-words: Asthma, Pharmacoeconomic studies, cost effectiveness analysis, cost minimization analysis, Anti-asthmatic drugs.
\end{abstract}

*Address for Correspondence:

Dr Garima Adhaulia, Department of Pharmacology and Therapeutics, K.G.M.U., Lucknow, Uttar Pradesh, INDIA.

Email: drgarima.26@gmail.com

Received Date: 14/11/2019 Revised Date: 30/12/2019 Accepted Date: 22/01/2020

DOI: https://doi.org/10.26611/10101421

\begin{tabular}{|l|l|}
\hline \multicolumn{2}{|c|}{ Access this article online } \\
\hline Quick Response Code: & Website: \\
& www.medpulse.in \\
\cline { 2 - 2 } & \\
\hline
\end{tabular}

\section{INTRODUCTION}

Pharmacoeconomics is defined as refers to the scientific discipline that compares the value of one pharmaceutical drug or drug therapy to another ${ }^{1}$. Asthma affects approximately 339.4 million individuals worldwide ${ }^{2}$. Disease can affect any age group but is high among children and adolescents with an estimated range of 3-38\% in children and $2-12 \%$ in adults ${ }^{3}$. Chronic nature of the disease require prolong treatment which increases the cost of the treatment, effects patient adherence towards treatment and also imposes economic burden on the patient ${ }^{4}$. The main goals of current asthma treatment is to achieve and maintain control of asthma symptoms, maintain normal activity levels, and to maintain pulmonary 
function as close to normal as possible, while reducing the potential for adverse effects and/or exacerbations ${ }^{5}$. In India, the estimated cost of asthma treatment per year for the year 2015 has been calculated to be approximately Rs. 139.45 billion $^{6}$. According to market reports there has been a drastic rise of $43 \%$ in the sale of anti-asthmatic drugs in 4 years $(2012-2016)^{7}$. So, the present study has been conducted to help us in interpreting various therapy options for the management of bronchial asthma and to compare the various economic parameters related to different treatment alternatives having optimum therapy with maximum safety and efficacy at low cost.

Aim: To compare the economic parameters of different treatment alternatives used for the management of bronchial asthma.

Objective: To perform a cost minimization and cost effectiveness analysis study for the various treatment alternatives being prescribed to the asthma patients in the department of Respiratory Medicine O.P.D K.G.M.U., Lucknow.

Subjects and Methods:

The present prospective, observational study was conducted in the Department of Pharmacology and Therapeutics, King George's Medical University, Lucknow in collaboration with Department of Respiratory Medicine OPD, King George's Medical University, Lucknow from November 2018 to August 2019. The study was started only after getting the ethical approval from the Institutional Ethics Committee of King George's Medical University, Lucknow. Total 114 patients who were diagnosed with asthma as primary disease were recruited after fulfilling our inclusion exclusion criteria.

Inclusion and exclusion criteria are as follows :

Inclusion criteria:

$>$ All patients diagnosed with bronchial asthma

$>$ Either sex - Male or Female

$>$ Patients within the age limit of 18 and above

$>$ Patients willing to get enrolled in a study with consent

Exclusion criteria:

$>$ Patients who are less than 18 years.

$>$ Patients not willing to participate or give consent.

$>$ Those patients who are not able to give interview.

$>$ Patients with associated co-morbidities such as HTN, Diabetes, Heart diseases, TB, HIV - AIDS.

$>$ Concurrent major psychiatric illness and/or concurrent major medical illness.

$>$ Patient with chronic illness and terminally end stage patients.

The procedure followed in this observational study was in agreement with the ethical standards of the authority committee on human experimentation (Institutional or national). Detailed history, signs and symptoms, physical examination and investigations like pulmonary function tests (PFTs) - spirometry, absolute eosinophilic count (AEC) and serum IgE levels were done to confirm the diagnosis of asthma. Data from the records were entered into a specially designed Case Report From (CRF) which included patients demographic details (patients name, age, sex, occupation, residence, OPD registration number), presenting complaints and their duration, history of cigarette smoking, family history of asthma, any previous treatment history or current treatment, associated comorbidities (such as HTN, Diabetes, TB, AIDS, heart disease etc), investigations related to diagnosis [mainly spirometry which was performed using spirometer (pulmonary function equipment) of Cosmed company for evaluation of forced vital capacity (FVC), forced expiratory volume at 1 minute $\left(\mathrm{FEV}_{1}\right), \mathrm{FEV}_{1} / \mathrm{FVC}$ ratio. Other investigations like average eosinophilic count (AEC), serum IgE levels, were also performed], drugs prescribed for asthma along with dosage, duration, frequency and route of administration and cost of total therapy. On confirming the diagnosis of asthma, the prescriptions forms were collected from the patient and relevant information satisfying the objective of the study were noted on the case report form (CRF). The patients was followed up at $4^{\text {th }}$ week (1month $)$ and $12^{\text {th }}$ week (3 month) and 6 months for clinical improvement and for any additional medication. The data obtained from the prescription regarding cost of anti-asthmatic drugs was assessed and evaluated using appropriate statistical tests on the completion of study. The economic data (direct cost of treatment) was obtained from patients bill, hospital and pharmacy billing for pharmacoeconomic evaluation. Cost of various drugs was calculated from current index of medical specialities (CIMS oct 2018- Jan 2019) and Bureau of pharma PSUs of India (BPPI)- janaushadhi site. Statistical analysis: Cost were mentioned in mean and standard deviation. Data obtained from cost effectiveness were subjected to one way analysis of variance (ANOVA) amongst multiple groups. Analyzed data was presented in a tabulated and by graphical presentation.

\section{RESULTS}

\section{Cost Minimization Analysis (CMA)}

Cost minimization analysis is conducted to determine the variation in cost of anti-asthmatic drugs being prescribed which is expressed in \% cost variation. \% cost variation analysis of individual (single class prescribed) and combination (FDCs) drug therapy were analysed using the maximum and minimum cost of the anti- asthmatic medications. From the results of our study, among the single prescribed drug maximum $\%$ cost variation was seen with steroids (203.5\%) whereas minimum percentage cost variation was seen with anticholinergics (51.5\%). 
Similarly, among combination drugs maximum \% cost variation was seen with combination of leukotriene receptor modifiers and antihistaminics [montelukast +levocetrizine] (706.25\%), whereas minimum percentage cost variation was observed for combination of steroid and LABA [budesonide + formoterol] (13.4\%).

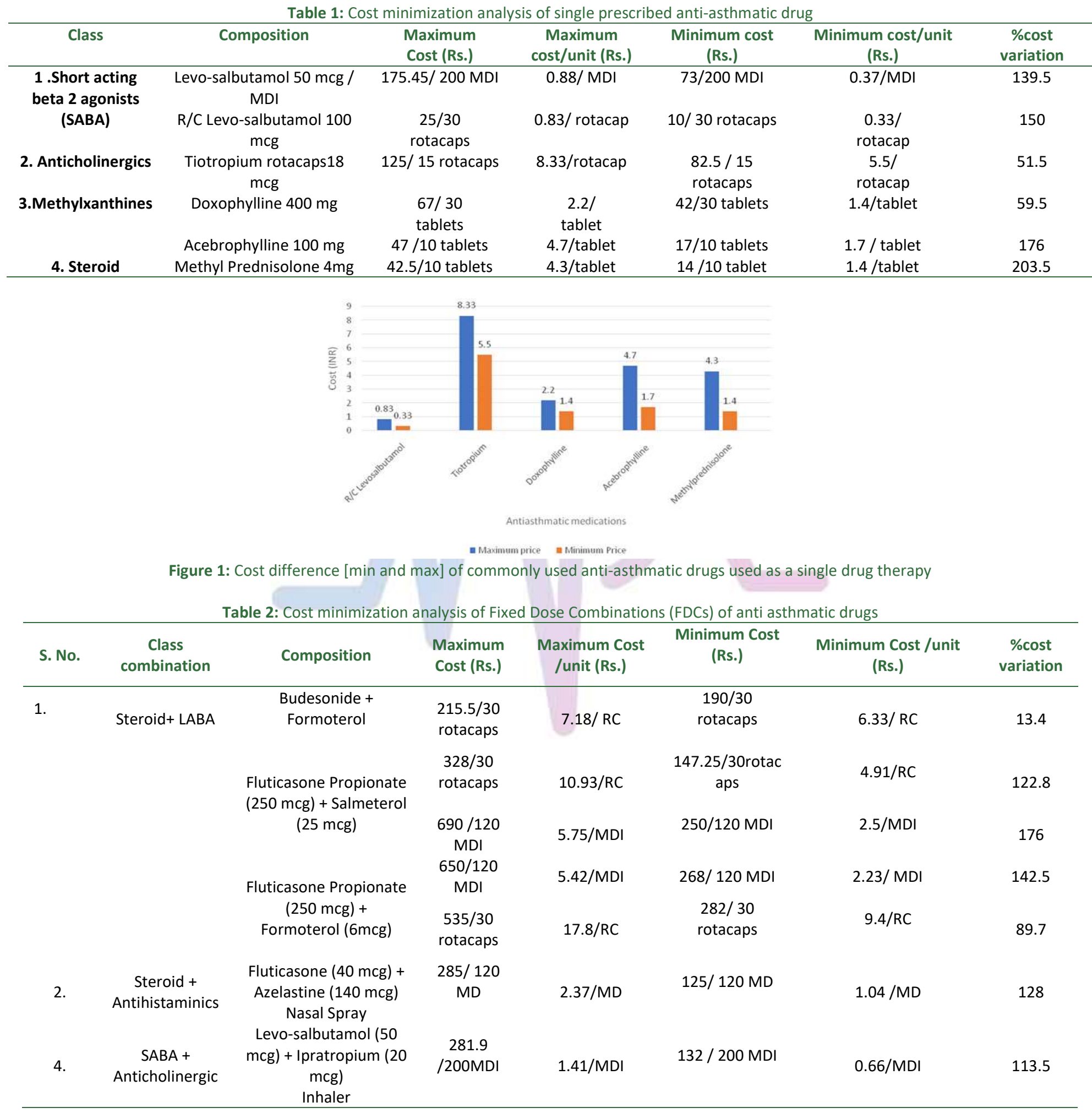




\begin{tabular}{|c|c|c|c|c|c|c|c|}
\hline \multirow[t]{2}{*}{5.} & $\begin{array}{c}\text { Leukotriene } \\
\text { Receptor } \\
\text { Modifier }+ \\
\text { Antihistaminics }\end{array}$ & $\begin{array}{c}\text { Montelukast }(10 \mathrm{mg})+ \\
\text { levocetrizine }(5 \mathrm{mg}) \\
\text { Tablet }\end{array}$ & $\begin{array}{l}\text { 129/10 } \\
\text { tablets }\end{array}$ & 12.9/ tablet & $16 / 10$ tablet & 1.6/ tablet & 706.25 \\
\hline & & $\begin{array}{l}\text { Montelukast }(10 \mathrm{mg})+ \\
\text { Fexofenadine }(120 \mathrm{mg}) \\
\text { Tablet }\end{array}$ & $\begin{array}{c}\text { 142/ } 10 \\
\text { tablet }\end{array}$ & 14.2/ tablet & 37 / 10 tablets & 3.7/ tablet & 283.7 \\
\hline 6. & $\begin{array}{l}\text { Methylxanthine } \\
+ \text { LR Modifiers }\end{array}$ & $\begin{array}{c}\text { Acebrophylline (200 } \\
\text { mg) + Montelukast (10 } \\
\text { mg) } \\
\text { Tablet }\end{array}$ & $\begin{array}{l}\text { 189/ } 10 \\
\text { tablets }\end{array}$ & $\begin{array}{l}\text { 18.9/ } \\
\text { tablet }\end{array}$ & $50 / 10$ tablets & 5/ tablet & 278 \\
\hline
\end{tabular}

*in cases where generic of the asthmatic drugs were not available for taking the minimum cost, there the cheapest and the most frequently prescribed formulation were taken as the comparator drug for taking the cost variation.

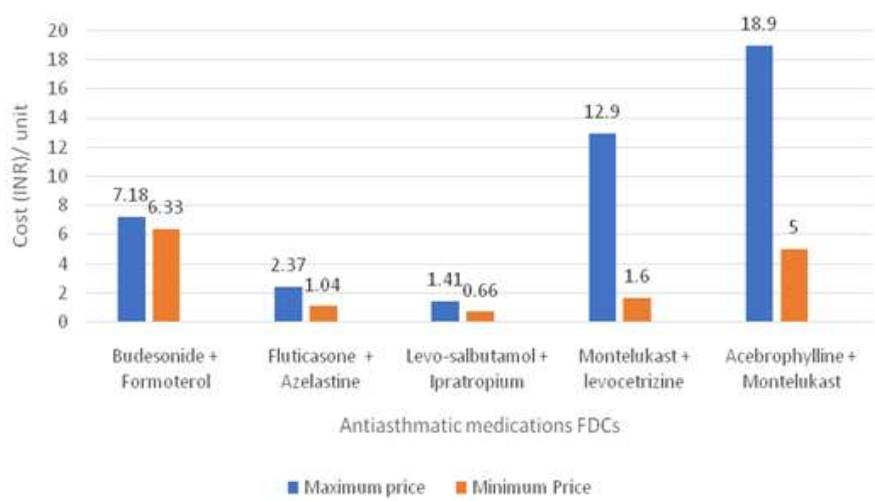

Figure 2: Cost difference [min and $\mathrm{max}$ ] in combination (FDCs) of anti-asthmatic drugs

Drug acquisition cost (daily and annually)

Average total annual cost of anti-asthma medications is mentioned in the table below. Among single prescribed group of anti-asthmatic drugs minimum annual drug cost was for Rota-Cap levosalbutamol (423.5 INR) and maximum annual cost was for R/C tiotropium rotacaps $18 \mathrm{mcg}$ (2518.5 INR). Similarly, among FDCs of anti-asthmatic drug, minimum annual drug cost was for Inhaler [levo-salbutamol $(50 \mathrm{mcg})+$ ipratropium $(20 \mathrm{mcg})](657 \mathrm{INR})$ and maximum annual cost was for Rota Cap combination of $[\mathrm{R} / \mathrm{C}$ fluticasone Propionate $(250 \mathrm{mcg})+$ formoterol $(6 \mathrm{mcg})]$ with a total annual drug acquisition cost of 9928 INR.

Table 3: Drug acquisition cost (daily and annually) for antiasthmatic drug according to class of drugs

\begin{tabular}{|c|c|c|}
\hline Drug Class & Cost per day (mean + S.D.) & Cost per year (mean+ S.D.) \\
\hline Inhaler Levo-salbutamol 50 mcg & $1.25(0.36)$ & $456.25(131.45)$ \\
\hline R/C Levo-salbutamol 100 mcg & $1.16(0.44)$ & $423.4(160.66)$ \\
\hline $\mathrm{R} / \mathrm{C}$ Tiotropium rotacaps $18 \mathrm{mcg}$ & $6.9(3.57)$ & $2518.5(1303.05)$ \\
\hline Tab. Doxophylline 400 mg & $3.6(1.24)$ & $1314(452.6)$ \\
\hline Tab. Acebrophylline $100 \mathrm{mg}$ & $6.4(3.18)$ & $2336(1160.7)$ \\
\hline Tab. Methyl Prednisolone 4mg & $5.7(2.91)$ & $2080(1062.15)$ \\
\hline R/C Budesonide + Formoterol & $13.51(8.54)$ & 4931.15 (3117.1) \\
\hline R/C Fluticasone Propionate (250 mcg) + Salmeterol ( $25 \mathrm{mcg}$ ) & $15.83(11.56)$ & 5777.95 (4219.4) \\
\hline R/C Fluticasone Propionate $(250 \mathrm{mcg})+$ Formoterol $(6 \mathrm{mcg})$ & $27.2(10.85)$ & $9928(3960.25)$ \\
\hline $\mathrm{N} / \mathrm{S}$ Fluticasone $(40 \mathrm{mcg})+$ Azelastine $(140 \mathrm{mcg})$ & $3.41(1.19)$ & 1244.65 (434.35) \\
\hline Inhaler & $1.8(0.64)$ & $657(233.64)$ \\
\hline \multicolumn{3}{|l|}{ Levo-salbutamol (50 mcg) + Ipratropium (20 mcg) } \\
\hline Tab. Montelukast (10mg) + levocetrizine (5mg) & $14.5(9.72)$ & $5292.5(3547.8)$ \\
\hline Tab. Montelukast (10mg) + Fexofenadine (120mg) & $17.9(6.48)$ & $6533.5(2365.2)$ \\
\hline Tab. Montelukast (10 mg) + Acebrophylline (200 mg) & $23.9(5.36)$ & $8723.5(1956.4)$ \\
\hline
\end{tabular}




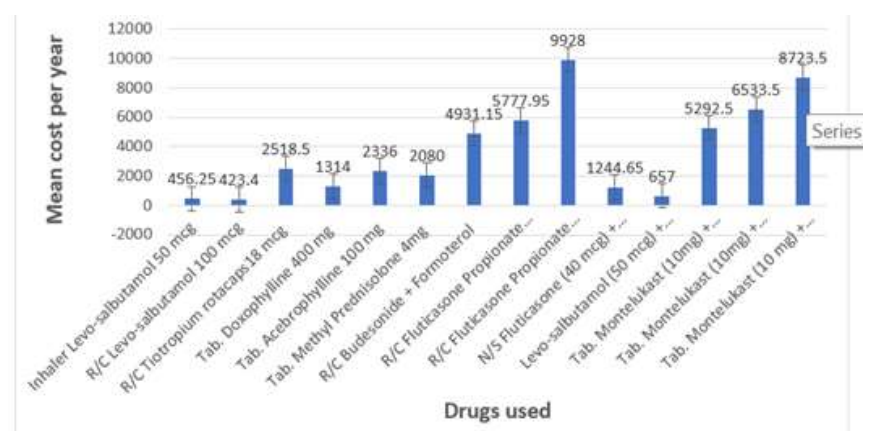

Figure 3: Average total annual cost of anti-asthma medications

\section{Cost Effective Analysis (CEA)}

Cost effectiveness of anti-asthmatics was analysed by using average cost effectiveness ratio (ACER) and incremental cost effectiveness ratio (ICER). cost incurred in rupees (INR) for improvement in $\mathrm{FEV}_{1} \%$ were calculated and assessed.

In this study all patients were on either two, three or four drug therapy (multiple/ polytherapy) and no patients were given single drug therapy (monotherapy) As shown in Table 2, overall the maximum mean improvement in $\mathrm{FEV}_{1} \%(18.3 \%)$ was seen with four drug combination of [Steroid + LABA, SABA + anticholinergic, methylxanthines and LTRA ] and minimum mean improvement in $\mathrm{FEV}_{1} \%$ (9.4\%) was seen with two drug combination of [Steroid+ LABA, LTRA]

When compared among three drug combination group the maximum mean improvement in $\mathrm{FEV}_{1}(13.6 \%)$ was seen with combination of [Steroid+ LABA, salbutamol (SABA) and LTRA]

The cost per unit improvement in FEV 1 (ACER) was highest (Rs. 29.55) with four drug combination of [Steroid + LABA, salbutamol (SABA), anticholinergic and LTRA] and lowest (Rs. 22.40) with four drug combination of [Steroid + LABA, SABA + anticholinergic, methylxanthines and LTRA] In terms of ICER, in the analysis of prescription with four drugs combination of [Steroid + LABA,SABA + anticholinergic, methylxanthines, LTRA] as comparator, rest of the four drug combinations showed a negative ICER value which indicates that the comparator [Steroid + LABA,SABA + anticholinergic, methylxanthines, LTRA] was the most cost effective.Similarly, in the analysis of prescription with three drugs combination of [Steroid, SABA + anticholinergic, LTRA] as comparator, the combination of [Steroid+ LABA, salbutamol (SABA), LTRA] was found to be most cost effective (ICER=14.5) Also, in the analysis of prescription with two drugs combination of [Steroid+ LABA, LTRA] as comparator, the combination of [steroid+ LABA, methylxanthines ] was found to be most cost effective (ICER=8.8)

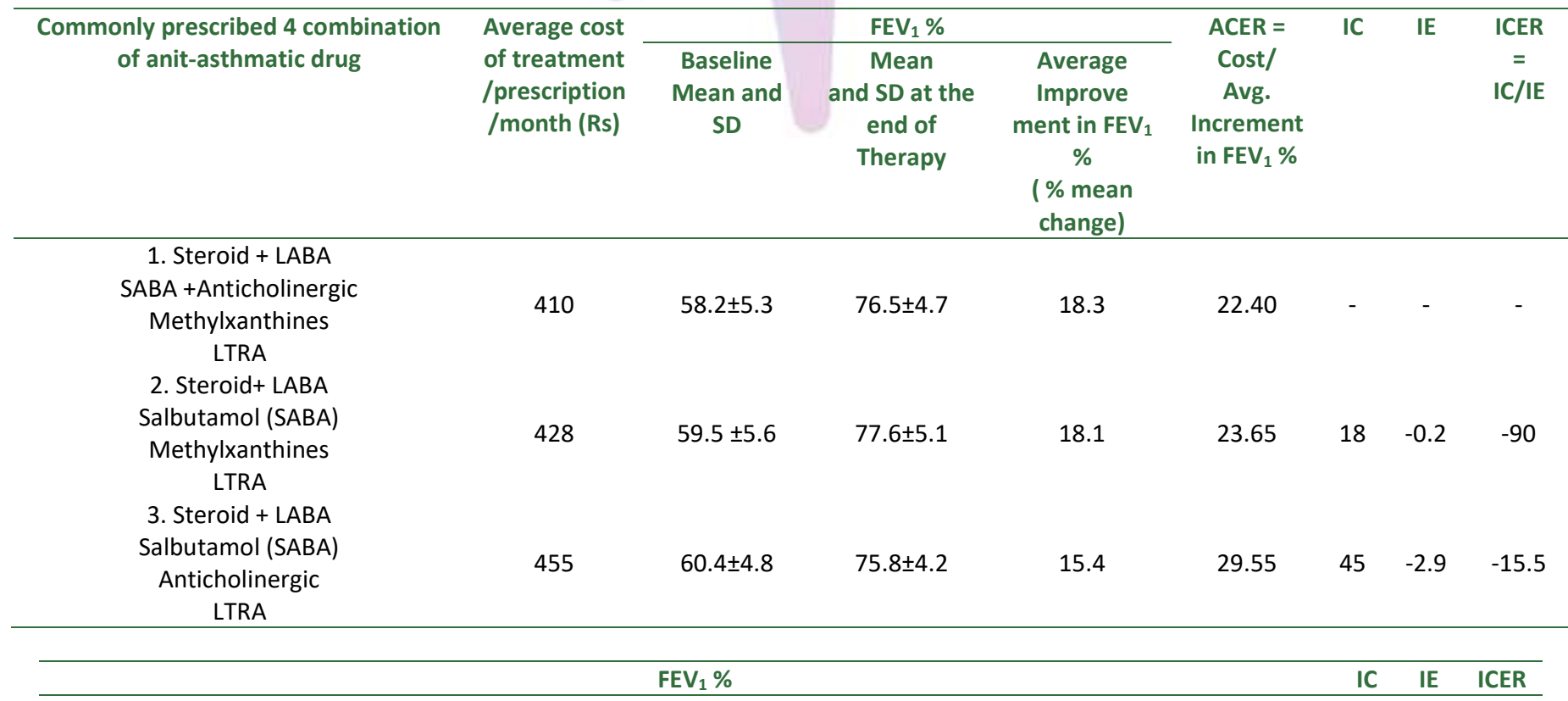




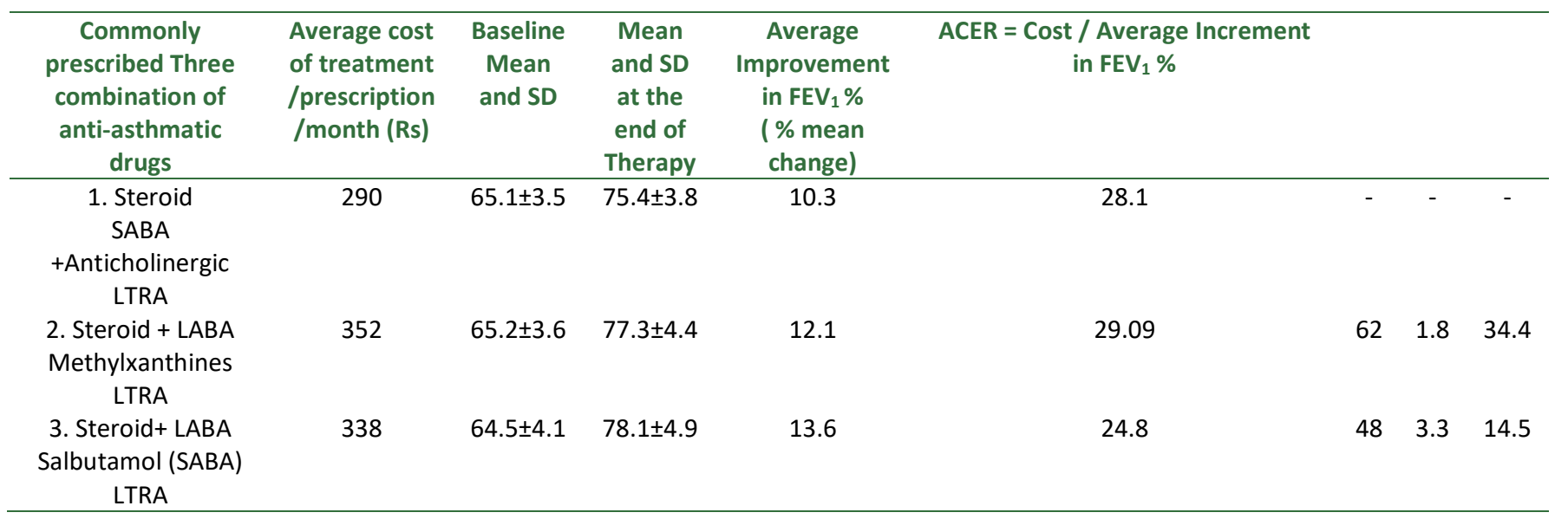

Commonly prescribed Two
combination of anti-
asthmatic drugs

asthmatic drugs

Table 4: Cost effective analysis of anti-asthmatic drugs (ACER , ICER)

\begin{tabular}{|c|c|c|c|c|c|c|c|c|}
\hline \multirow{2}{*}{$\begin{array}{l}\text { nmonly prescribed Two } \\
\text { combination of anti- } \\
\text { asthmatic drugs }\end{array}$} & \multirow{2}{*}{$\begin{array}{l}\text { Average cost of } \\
\text { treatment } \\
\text { /prescription } \\
\text { /month (Rs) }\end{array}$} & \multicolumn{3}{|c|}{$\mathrm{FEV}_{1} \%$} & \multirow{2}{*}{$\begin{array}{l}* \text { ACER }=\text { Cost } / \\
\text { Average } \\
\text { Increment in } \\
\text { FEV }_{1} \%\end{array}$} & \multirow[t]{2}{*}{ *IC } & \multirow[t]{2}{*}{ *IE } & \multirow[t]{2}{*}{ *ICER } \\
\hline & & $\begin{array}{l}\text { Baseline } \\
\text { Mean } \\
\text { and SD }\end{array}$ & $\begin{array}{l}\text { Mean and } \\
\text { SD at the } \\
\text { end of } \\
\text { Therapy }\end{array}$ & $\begin{array}{c}\text { Average } \\
\text { Improvement in } \\
\text { FEV }_{1} \% \\
\text { ( } \% \text { mean change) }\end{array}$ & & & & \\
\hline $\begin{array}{l}\text { 1. Steroid+ LABA } \\
\text { LTRA }\end{array}$ & 275 & $68.3 \pm 3.8$ & $77.7 \pm 3.5$ & 9.4 & 29.26 & - & - & - \\
\hline $\begin{array}{l}\text { 2. Steroid+ LABA } \\
\text { Salbutamol }\end{array}$ & 296 & $67.6 \pm 4.3$ & $78.8 \pm 3.9$ & 11.2 & 26.43 & 21 & 1.8 & 11.6 \\
\hline $\begin{array}{l}\text { 3. Steroid+ LABA } \\
\text { Methylxanthines }\end{array}$ & 290 & $67.1 \pm 3.6$ & $78.2 \pm 3.4$ & 11.1 & 26.1 & 15 & 1.7 & 8.8 \\
\hline
\end{tabular}

* IC - Incremental Cost, IE - Incremental Effect, ICER - Incremental Cost Effectiveness Ratio, ACER - Average Cost Effectiveness Ratio

Table 5: (ANOVA) Analysis of variance for anti - asthmatic drug therapy groups

\begin{tabular}{cccccc}
\hline & Sum of squares & DF & Mean squares & F value & P value \\
\hline Between Groups & 8.798689 & 4 & 2.199672 & 0.194271 & 0.929 \\
Within Groups & 45.29087 & 4 & 11.32272 & - & - \\
Total & 54.08956 & 8 & - & - & - \\
\hline *DF Degree of freedom & & & &
\end{tabular}

Data from cost effectiveness ratio was subjected to analysis of variance (ANOVA) to determine whether there is any significant difference in ACER (average total direct cost per unit improvement in $\mathrm{FEV}_{1}$ ) between different treatment anti-asthmatic drug therapy groups. Difference in ACERs between anti-asthmatic drug therapy groups was insignificant $(\mathrm{p}=0.929225)$, indicating all the groups are equally preferred depending upon the asthma severity and patient profile.

\section{DISCUSSION}

Cost minimization analysis is conducted to determine the variation in cost of anti-asthmatic drugs being prescribed, which is expressed in \% cost variation. Percentage cost variation for single prescribed anti-asthmatic drugs showed minimum \% cost variation with anticholinergics $(51.5 \%)$ and maximum $\%$ cost variation was observed with steroids (203.5\%). Similarly, among combination antiasthmatic drugs (FDCs) minimum \% cost variation was observed with combination of steroid and LABA [budesonide + formoterol] (13.4\%) while maximum \% cost variation was seen with combination of leukotriene receptor modifiers and anti-histaminics [ montelukast + levocetrizine] (706.25\%). This data suggests that multiple brands were available for steroids and combination of leukotriene receptor modifiers and anti-histaminics in a wide range of price. Lower price drugs should be prescribed for cost minimization. Similarly, in other class of drugs also multiple brands are available and wise selection of cheaper and effective brands by the physician can minimize total cost of therapy. In a study by Dharani D et al... ${ }^{8}$, cost analysis of different class of anti-asthmatic drugs, showed that in single drug therapy minimum and maximum \% cost variation was shown by inhalational steroids $(0.27 \%)$ and Theophylline $(788.88 \%)$ respectively and among the combination therapy minimum and maximum $\%$ cost variation was shown by formoterol + budesonide combination $(0.37 \%)$ and salbutamol + 
theophylline combination (900\%) respectively. The difference in the results may be attributed to the different drug brands available in different regions of the world. For single prescribed group of anti-asthmatic drugs minimum annual cost was for Rota-Cap levo-salbutamol (423.5 INR) and for FDCs minimum annual cost was Inhaler [levosalbutamol $(50 \mathrm{mcg})+$ ipratropium $(20 \mathrm{mcg})]$ (657 INR). This findings suggests that more prescription of these drugs will result in decreased overall cost of the therapy. Cost effectiveness of anti-asthmatics drugs was analysed using average cost effectiveness ratio (ACER) and incremental cost effectiveness ratio (ICER). Cost incurred in rupees (INR) for improvement in $\mathrm{FEV}_{1} \%$ were calculated and assessed. The cost per unit improvement in $\mathrm{FEV}_{1}$ (ACER) was highest (Rs. 29.55) with four drug combination of [Steroid + LABA, salbutamol (SABA), anticholinergic, LTRA] and lowest (Rs. 22.40) with four drug combination of [Steroid + LABA, SABA + anticholinergic, methylxanthines, LTRA ].This suggests that four drug combination of [Steroid + LABA, SABA + anticholinergic, methylxanthines, LTRA ] is the most cost effective anti-asthmatic drug therapy. However, when data from cost effectiveness ratio was subjected to analysis of variance (ANOVA) to determine whether there is any significant difference in ACER (average total direct cost per unit improvement in $\mathrm{FEV}_{1}$ ) between different treatment anti-asthmatic drug therapy groups $(4,3,2$ drug groups), the difference in ACERs was found to be insignificant $(p=0.929)$. Thus, though the four drug combination of [Steroid + LABA, SABA + anticholinergic, methylxanthines, LTRA] has the lowest ACER but all the drug therapy groups (4,3,2 drug groups) are equally effective and preferred depending upon the asthma severity and profile of the patients. In terms of ICER, in the analysis of prescription with four drugs combination, keeping the combination of [Steroid + LABA, SABA + anticholinergic, methylxanthines, LTRA] as comparator, rest of the four drug combinations showed a negative ICER value which indicates that the comparator [Steroid + LABA, SABA + anticholinergic, methylxanthines, LTRA] was the most cost effective among the all four drug therapies. Similarly, in the analysis of prescription with three drugs combination, the combination of [Steroid+ LABA, salbutamol (SABA), LTRA] was found to be most cost effective (ICER=14.5). Also, in the analysis of prescription with two drugs combination, the combination of [Steroid+ LABA, methylxanthines] was found to be most cost effective $(\mathrm{ICER}=8.8)$. Thus, more prescriptions with the above mentioned drug combinations will improve the cost effectiveness of the anti-asthma therapy. In systematic review study conducted by Judy W M et al... ${ }^{9}$ comparing pharmacoeconomic analysis of various anti-asthmatic medication, combination available in USA, concluded that salmeterol-fluticasone is a cost effective treatment option for moderate persistent asthma management. When compared with fluticasone with or without the addition of leukotriene receptor antagonist (LTRA) concluded that LTRA are less cost effective than inhaled corticosteroid (ICS) or combined ICS and LABA for mild to moderate persistent asthma.

\section{CONCLUSION}

Asthma being a chronic illness requiring prolonged treatment, even a small cost variation can have significant economical implications. Health professionals must prescribe rationally, choosing cost effective medicines based on country's health situation and according to guidelines. From the present study it has been concluded that the most cost effective therapy (ACER $=$ Rs.22.04) for asthma is a multiple drug therapy of four drug combination of [Steroid + LABA, SABA + anticholinergic, methylxanthines, LTRA]

\section{ACKNOWLEDGEMENT}

I want to express my gratitude to faculty and staff of department of Respiratory Medicine and department of Pharmacology and Therapeutics K.G.M.U., Lucknow as well as to all my co -authors for their contribution and support.

\section{REFERENCES}

1. Ahmad A, Patel I. The role of pharmacoeconomics in current Indian healthcare system. Journal of Research in Pharmacy Practice. 2013;2(1):3-9 ].

2. Global Asthma Network The Global Asthma Report [Internet]. 2018 [cited 2019 Sep 9]. Available from:http://www.globalasthmareport.org/Global $\% 20$ Asthma\%20Report\%202018.pdf

3. Cavkaytar O, Sekerel B.E. Baseline management of asthma control. Allergol Immunopathol (Madr). 2014;42:162-8.

4. Kant S. Socio-economic dynamics of asthma. Indian J Med Res. 2013;138(4):446-8.

5. Aggarwal AN, Chaudhry K, Chhabra SK, D'Souza GA, Gupta D, Jindal SK, et al.... Prevalence and risk factors for bronchial asthma in Indian adults: A multicentre study. Indian J Chest Dis Allied Sci. 2006;48:13-22

6. MINISTRY OF HEALTH AND FAMILY WELFARE GOVERNMENT OF INDIA, 2005 Background Papers of the National Commission on Macroeconomics and Health EQUITABLE DEVELOPMENT • HEALTHY FUTURE [Internet]. [cited 2019 Sep 3]. Available from: http://citeseerx.ist.psu.edu/viewdoc/download?doi=10.1.1 .168 .1768 andrep $=$ rep 1 andtype $=$ pdf

7. World Asthma Day: India chokes, sales of medicines rise $43 \%$ in 4 years $\mid$ health $\mid$ Hindustan Times [Internet]. [cited 2019 Sep 9]. Available from: https://www.hindustantimes.com/health/world-asthma- 
day-india-chokes-sales-of-medicines-rise-43-in-4years/story-mt5V9Kdqv4yGF062ZOmC6I.html

8. Dharani D, Shashirekha C.H, Shruthi S.L. Cost analysis study of different brands of commonly used drugs for bronchial asthma available in India $-\mathrm{A}$ pharmacoeconomic study. Indian Journal of Pharmacy and Pharmacology. 2017;4(4):176-183.

9. Judy W.M et al.... Pharmacoeconomic review of medical management of persistent asthma. Allergy and Asthma Proceedings.2008;29(2):109-122

\section{Source of Support: None Declared} Conflict of Interest: None Declared 